\title{
Teacher Attitude towards Use of Chatbots in Routine Teaching
}

\author{
Bii P. K ${ }^{1, *}$, J. K. Too ${ }^{2}$ C. W. Mukwa ${ }^{2}$ \\ ${ }^{1}$ Department of Mathematics and Computer Science, University of Kabianga, Kericho, Kenya \\ ${ }^{2}$ Department of Curriculum Instruction and Educational Media, School of Education, Moi University, Kenya
}

Copyright $(\mathrm{C} 2018$ by authors, all rights reserved. Authors agree that this article remains permanently open access under the terms of the Creative Commons Attribution License 4.0 International License

\begin{abstract}
Teacher's attitude towards some particular technology influences their willingness to use that technology in their instructional processes, and consequently the attitude and responses of students to the technology that they observe teachers using. This has a direct bearing on whether or not such technology will successfully be integrated into routine classroom practice and whether benefits of using such technology for teaching-learning purposes will be realized. This study sought to ascertain the attitude of teachers towards use of chatbot technology for teaching and learning purposes, chatbots being yet an emerging educational technology within a majority of developing countries including Kenya.
\end{abstract}

Keywords Teacher Attitude, Educational Chatbot, Educational Software, Chatbot, Chatbot Technology, Educational Technology, Integration, Social Constructivism

\section{Introduction}

Chatbots are a group of computer programs that are deliberately designed to be social and interactive in nature. Their goal is to simulate intelligent human language interaction through text or speech through engaging in informal chat communication between a human user and a computer using natural language [1-3]. The first chatbot, named ELIZA, was created by Joseph Wiezenbaum of MIT to emulate a psychotherapist in clinical treatments [4]. This was followed by chatbot PARRY developed by Kenneth Colby of Stanford University in 1972 to simulate a paranoid schizophrenic [3]. In 1995, Richard Wallace of Carnegie Mellon University developed the chatbot ALICE (Artificial Linguistic Internet Computing Entity), based on AIML (Artificial Intelligence Markup Language), which is designed to converse with a user on almost any topic of interest [4]. The technology behind ALICE and AIML was released in 2001, and this led to the implementation of various general conversational chatbots based on AIML. The chatbots generally available are internet-based and are mostly used for non-instructional purposes as the sample chatbot summary in Table 1 [5-8] shows.

As an educational technology, chatbots can potentially be used in a wide variety of ways in instructional settings. Kowalski, Hoffman, Jain \& Mumtaz [7] note that they can play a useful role for educational purposes, because they are an interactive mechanism as compared to traditional e-learning systems. They allow continuous student interaction by enabling them to ask questions related to a specific field. However, they go on to add that their use for instructional purposes is still limited. Jia \& Chen [9] in a study investigated how a chatbot could be used to motivate learners to practice English. The chatbot used was web-based and in the study they reviewed free internet usage of the chatbot over a six-month period. Additionally, the study evaluated the integration of the chatbot into English instruction in a high school classroom over a school term. Among the results of their study were the findings that students feel the approach can help with course unit review, make them more confident, improve their listening ability, and enhance interest in language learning. Investigations outside language speaking and learning are far more limited. Kerfoot, Baker, Jackson, Hulbert, Federman, Oates \& DeWolf [10] described an experiment in which chatbots were used in the training of medical students. The benefits of use of their web-based chatbots in teaching were significant increase of test scores in four topics and a three-fold increase in learning efficiency. Knill, Carlson, Chi and Lezama [11] investigated the use of a chatbot called Sofia in the teaching and learning of Mathematics with their conclusion being that a chatbot adds to the variety of tools available for student instruction. 
Table 1. Sample Chatbots and Their Communication Modes

\begin{tabular}{|c|c|c|}
\hline General Chatbots & Application & Communication Mode \\
\hline ELIZA & Programmed to act as a Rogerian therapist & $\begin{array}{l}\text { Input: Textual mode } \\
\text { Output: Textual mode }\end{array}$ \\
\hline Jabberwacky & Teachable chatbot & $\begin{array}{l}\text { Input: textual mode } \\
\text { Output: textual and } \\
\text { Spoken mode. } \\
\end{array}$ \\
\hline Jenny & General wide vocabulary, replies often out of context & Textual mode \\
\hline Sanelma & $\begin{array}{l}\text { A fictional person to talk with in a museum, which provides } \\
\text { background information concerning a certain piece of art. }\end{array}$ & Textual mode \\
\hline PC Therapist & $\begin{array}{l}\text { Simulate a Rogerian therapist, inspired from ELIZA. Different } \\
\text { personalities have been developed such as: PC professor } \\
\text { discusses men versus women; PC Politician discusses Liberals } \\
\text { versus Conservatives. }\end{array}$ & Spoken mode \\
\hline Marloes & A female Dutch financial advisor. & Spoken mode \\
\hline MIA & A German advisor on opening a bank account. & Textual mode \\
\hline Cybelle & $\begin{array}{l}\text { A female avatar with body and uses gestures while talking. She } \\
\text { directs you to discover the agent land, a new land where you can } \\
\text { find more information about agents, what they are, how they } \\
\text { work, how they could be useful for you. }\end{array}$ & Textual mode \\
\hline Ultra Hal & $\begin{array}{c}\text { Programmed to learn by statistically analyzing } \\
\text { past conversations to determine the most appropriate } \\
\text { response }\end{array}$ & $\begin{array}{c}\text { Supports a number of } \\
\text { speech and graphics engines and will } \\
\text { operate on the Web, and on } \\
\text { Windows, iPhone, Second Life, } \\
\text { Twitter, and Facebook. }\end{array}$ \\
\hline Pixel & $\begin{array}{c}\text { An AIML chatbot written to answer general questions about the } \\
\text { library and helps users at the University of Nebraska-Lincoln } \\
\text { Libraries }\end{array}$ & $\begin{array}{l}\text { Input: textual mode } \\
\text { Output: Textual mode }\end{array}$ \\
\hline $\begin{array}{c}\text { Educational } \\
\text { Chatbots }\end{array}$ & Application & $\begin{array}{c}\text { Communication } \\
\text { Mode }\end{array}$ \\
\hline Dave & $\begin{array}{l}\text { The A. I. Chat Robot DAVE the English Teacher replies in } \\
\text { perfect English just like a private English teacher or human chat } \\
\text { partner. With tens of thousands of words in its vocabulary, he is } \\
\text { the perfect private tutor. }\end{array}$ & $\begin{array}{l}\text { Input: textual mode } \\
\text { Output: spoken and } \\
\text { textual mode. }\end{array}$ \\
\hline Speak2Me & $\begin{array}{l}\text { A female chatbot that is used to teach English language through } \\
\text { chatting. }\end{array}$ & $\begin{array}{l}\text { Input: textual mode } \\
\text { Output: spoken and } \\
\text { textual mode. }\end{array}$ \\
\hline Percy & Computer Science Teaching Assistant & Textual mode \\
\hline $\begin{array}{l}\text { Virtual Patient bot } \\
\text { (VPbot) }\end{array}$ & Medical students education bot & Textual mode \\
\hline
\end{tabular}

Sources: [5-8]

As of now, not much research has been conducted in developing countries to uncover specific ways of use of chatbots in classrooms, what the key players of teachers and students think of the technology, and actual benefits of use, though research on uses of computers in instruction, use of chatbots in some instructional contexts, and specific use of chatbots in the teaching of English in non-English speaking countries (also to a limited extent) is extant [12-14]. There is then a need for systematic integration, application and evaluation studies to widen findings and scope. A majority of the aforementioned studies also do not consider chatbots from the teacher's perspective. Investigation of the various factors and dimensions affecting teachers with regard to use of chatbots in teaching is important since teachers are an indispensible part of the teaching-learning environment. One such dimension pertaining to the teacher is their attitude towards use of chatbots in their teaching activities. This study therefore sought to determine the attitude of teachers towards use of chatbots in teaching in two randomly selected secondary schools within Buret District, Kericho County, Rift Valley Province, and the Republic of Kenya. It was undertaken within the context of a broader study that sought to establish the effect of use of chatbot technology on interaction and collaboration patterns in teaching and learning undertaken from a social-constructivist point of view. Within the Kenyan context, Nchunge, Sakwa \& Mwangi [15, p17] noted that 'while there is a wide range of innovations in ICT to support effective and quality delivery of education services and curricula, there is a considerable technology lag in educational institutions. Most institutions still use nearly obsolete systems and are consequently unable to exploit the educational potential of the emerging technologies'. The attitude of teachers towards technologies that they are encouraged and expected to use in their teaching is critical, since this influences their 
willingness to actively use them in routine teaching and transfer the same enthusiasm of use to the students under them $[16,17]$. Their attitude also influences their rate of adoption of emergent technologies that can be of use in educational settings [18 - 21]. Fu [22] noted that teacher attitudes toward technology are significant predictors of teacher and student technology use, as well as of their use of a variety of instructional strategies.

The chatbot used in the study is named Knowie. This chatbot was derived by the author from the open source chatbot Howie originally created by Stratton [23], which the author downloaded and modified for educational research and application purposes. The chatbot was programmed using the Python programming language, with its knowledge base being implemented using AIML. Several approaches can be used to add knowledge to a chatbot. These approaches include starting with an empty database to which content is automatically added as the chatbot is used, having the chatbot designer program the database so that it has pre-programmed questions, phrases or words and how it is to respond to each question, phrase or word, and enabling the chatbot to learn from text corpora [24]. The approach of starting with an empty knowledge base was implemented in the study, with the additional provision that teachers and students could deliberately add knowledge content to the chatbot through direct entry of question-answer pairs, direct entry of keyword-definition pairs, and typing of class notes into the bot for later keyword-definition pair searches and hence automatic generation of AIML pattern-template pairs for the bot's knowledge base. This approach of starting with an empty knowledge base was deliberately used in order to offer an opportunity for teachers to implement a social-constructivist teaching-learning environment with elements of social context, enhanced social interaction, collaboration, mediation and scaffolding [25] as per social-constructivist principles.

\section{Research Methodology}

\subsection{Research Design}

The methodology used in the study was mixed methods, more specifically, a repeated treatment quasi-experimental case study. Creswell [26, p.1] states that in a case study, the 'researcher explores in depth a program, an event, an activity, a process, or one or more individuals. The case(s) are bounded by time and activity, and researchers collect detailed information using a variety of data collection procedures over a sustained period of time'. Further, Savenye \& Robinson [27] note that researchers often conduct a case study to learn more unobtrusively about students, teachers, and trainers who use a new technology and that case studies present detailed data that create a picture of perceptions, use, attitudes, reactions, and learner/teacher environments. According to Zainal [28, p2], 'case studies, in their true essence, explore and investigate contemporary real-life phenomenon through detailed contextual analysis of a limited number of events or conditions, and their relationships'. Hence it was an appropriate approach to use in this study involving chatbot technology in a teaching-learning environment. Anwar Sheik \& Bibi [29] add that in it, an individual or an institution is studied in a unique setting or situation in an intense and detailed manner for long a period of time. A chatbot was installed in the computer laboratory in each of two randomly selected schools offering computer studies as an examination subject. Ten Form two teachers teaching these classes were then trained in the use of the chatbot in teaching. They subsequently trained the students to use the chatbot after which it was used for teaching-learning activities for 20 weeks (5 months) spread over two terms of the school year.

The design used in the study was quasi-experimental and structured to offer an opportunity to elicit quantitative data on teacher attitude obtained through questionnaire administration to teachers who participated in the study. In a quasi-experimental design, a programme or policy is viewed as an intervention in which a treatment comprising the elements of the programme or policy being evaluated - is tested for how well it achieves its objectives, as measured by a pre-specified set of indicators [30]. Quasi-experimental approaches are frequently used when it is not logistically feasible or ethical to conduct a randomized controlled trial [31]. The study specifically purposed to institute instances of chatbot technology use in two randomly selected school settings by two given classes and their teachers and then determine the attitude of participant teachers towards the use of the chatbot in instruction through a questionnaire administered after their experience of chatbot use in teaching-learning. According to Albirini [18, p375], 'a new technology will be increasingly diffused if potential adopters perceive that ... the innovation can be experimented with on a limited basis before adoption'. This is based upon the Trialability attribute of the technology as given by Rogers [32] and which influences the technologies' acceptance and subsequent adoption. Further, Perkins [33] noted that a trial period for an innovation will help potential adopters answer questions that they may have about that innovation. This study sought to offer participant teachers such an opportunity for experimentation over a period of five months spread over the first and second term of the school year, third term usually being occupied by National Exams in Kenyan Schools. It is beneficial for teachers to not only see how technology can be used to support and extend traditional pedagogy (thereby alleviating resistance to adoption), but also to see how technology can be used to create richer, more engaging, student centered approaches to knowledge acquisition by students, rather than limiting their use to notes preparation, tests preparation, and 
classroom management [22].

Questionnaire use for data collection has a number of advantages including affordability, ability to reach a large number of potential respondents in a limited time, efficiency, and standardization though it has some advantages for instance superficial responses, poor validation, and generation of vast quantities of data through open ended items which may be problematic to analyze [34]. These issues were addressed through addressing concerns such as appropriate questionnaire design and layout, clarity of instructions and language, length of questionnaire, and proper induction of the participants to the research study [35].

\subsection{Venue and Sample}

The research study was undertaken in Buret District, Kericho County, Rift Valley Province of the Republic of Kenya. One school was a Public Boy's Boarding School while the other school was a Public Girl's Boarding School. The total number of public schools offering computer studies as an examinable subject was obtained from the county education office as such schools would have their computer laboratories sufficiently equipped and functional to meet Government regulations [36]. This population was separated to form two groups, one for Girls' Schools and one for Boys' Schools. One school was then randomly picked from each group to give the Girls' School and the Boys' School which participated in the study. The researcher obtained the proper research permit from the government before proceeding to the schools of interest to conduct the study. The researcher visited the schools and after due introduction and permission from the school administration, installed chatbot Knowie in the computers in the computer laboratories of the two schools.

Discussion with the school administration concerning classes to be involved in the study led to the identification of Form Two as the level agreed upon to participate in the study. Considerations for settling upon the Form Two classes included issues such as the Form one students still have to be taught more in the handling of computer equipment, and upper forms (Form Three and Form Four) being prepared for externally administered examinations. Thus the Form level was determined purposively. Similar considerations were made in settling upon Physics and Computer Studies teachers as the study participant teachers. All the teachers teaching Form Two were however trained on chatbot use in the two schools to give the total number of ten teachers in the two schools for eventual attitude data collection and measurement.

\subsection{Data Collection Instruments}

The characteristic, or construct, that was measured for the teachers was their attitude towards chatbot use in teaching. Jain [37] states that attitude represents the positive or negative mental and neural readiness towards a person, place, thing or event and has a cognitive, affective and behavioral component. Such an indirect construct is commonly measured using items that are developed to assess the construct. The score attained by a respondent to the items designed to assess the construct will usually be taken as a measure of the construct of interest. The rating scale commonly used for measuring attitude is the Likert scale. The basis of the Likert scale is the notion that attitudes vary along a dimension from negative to positive, and 'the key to successful attitude measurement was to convey this underlying dimension to survey respondents, so that they could then choose the response option that best reflects their position on that dimension' [38, p2]. The implication of this is that of universal applicability, allowed variations in item wording as long as the negative-to-positive dimension is covered, and assignment of a common numerical code to gauge respondents view on a particular item and across all the items. Hence with multiple items in an attitude survey, the codes can be summed or averaged to give an indication of each respondent's overall positive or negative orientation towards that object [38].

A Likert Scale questionnaire containing twenty items was used to establish teacher attitude towards use of chatbots in teaching-learning. The attitude measurement items in the questionnaire were designed to elicit teacher attitude using a 5-point Likert scale (e.g. Chatbot use in learning helps to clarify topic content; 1 - Strongly Disagree, 2 - Disagree, 3 - Uncertain, 4 - Agree, 5 Strongly Agree). The items were arrived at after due consideration of similar items that have been used in teacher attitude studies relevant to computer use for teaching and learning by teachers in schools [39-42]. The number of such items in the questionnaire was eighteen. Teacher attitude towards chatbot use in their instruction was represented as an average score on the five-point scale, with a score above 3.00 taken as indicating positive attitude. Following these items was an item seeking to know whether or not the teacher was willing to chat again with the chatbot. Lastly, an open-ended item after the above nineteen items sought to elicit suggestions from participant teachers on how a chatbot could be further improved to better meet their teaching needs.

\subsection{Piloting}

A piloting school similar to the ones that were ultimately involved in the final study was earlier before study commencement purposively identified and the chatbot installed in the computer lab of that school. One Form Two class stream was then picked for involvement during the first piloting phase. Teachers teaching the class were trained on chatbot use, after which students were also trained with the assistance of the teachers that had been trained. The participant teachers and students received this 
initial training in the first two weeks of the term. Following this, the teachers and students used the chatbot for teaching-learning activities once a week for three weeks in first term of the school year (third week to fifth week), after which the teacher questionnaire was administered in two occasions a fortnight apart. This test-retest procedure provided data that was used to determine the reliability coefficient of the attitude questionnaire. Results were used to adjust the instrument accordingly, after which the final instrument was administered as outlined above using a second school. The results of this second piloting phase were used to establish the reliability coefficient of the final attitude questionnaire used in the study. The test-retest reliability coefficient for the teacher attitude towards chatbot use for their teaching instrument was 0.761 , which was adequate for the research purposes.

\subsection{Data Collection Procedures}

The total number of public schools offering computer studies as an examinable subject was obtained from the county education office. This was separated to form two groups, one for Girl's Schools and one for Boy's Schools. One school was then randomly picked from each group to give the Girl's School and the Boy's School which participated in the study. The researcher then visited the schools and after due introduction and permission from the school administration, installed the chatbot in the computers in the computer laboratories of the two schools. Discussion with the school administration considering classes to be involved in the study led to the identification of Form Two as the level agreed upon. Consideration included issues like the Form one students still having to be taught more in handling computer equipment, and upper forms being final internal and National examination preparation oriented. Thus the Form level was determined purposively. Similar considerations were made in settling upon Physics and Computer Studies teachers as the study participant teachers. The teachers who used the chatbot in actual teaching-learning activities were therefore two. However, all the teachers teaching Form Two were trained on chatbot use in the two schools to give the total number of teachers as ten for attitude measurement. The study was conducted for ten weeks in term one and ten weeks in term two to give a total duration of twenty weeks during which observations were conducted and teachers were exposed to use of chatbots for teaching-learning purposes. In order to determine the attitude that participant teachers had towards chatbot technology use in their teaching and to elicit their suggestions on how further the technology could be improved to better suit their needs, the teachers completed the questionnaire with relevant attitude-eliciting items after their experience of chatbot use in their teaching.

\subsection{Data Analysis Procedures}

The overall average rating for all attitude measurement items for the teachers who participated in the study was determined from the tallied responses per questionnaire item. Analysis of individual teacher responses to each questionnaire item was also carried out to ascertain majority teacher views per item and to note any peculiarities of responses. Teacher responses to the last open-ended item seeking chatbot improvement suggestions from them were analyzed, categorized, frequency tallied and sorted in descending order to indicate overall priority for solution.

\subsection{Results and Discussion}

The percentage responses to each of the items in the teacher questionnaire given by the respondents are presented in the following charts.

Teacher responses to each of the items in the questionnaire were as follows:

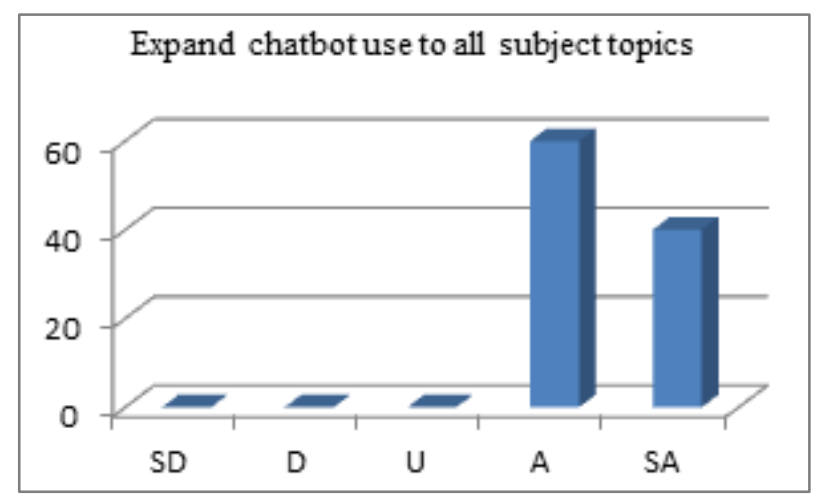

Item 1. Expand chatbot use to all subject topics

All the teachers agreed that chatbot use be expanded to all topics in their teaching subject.

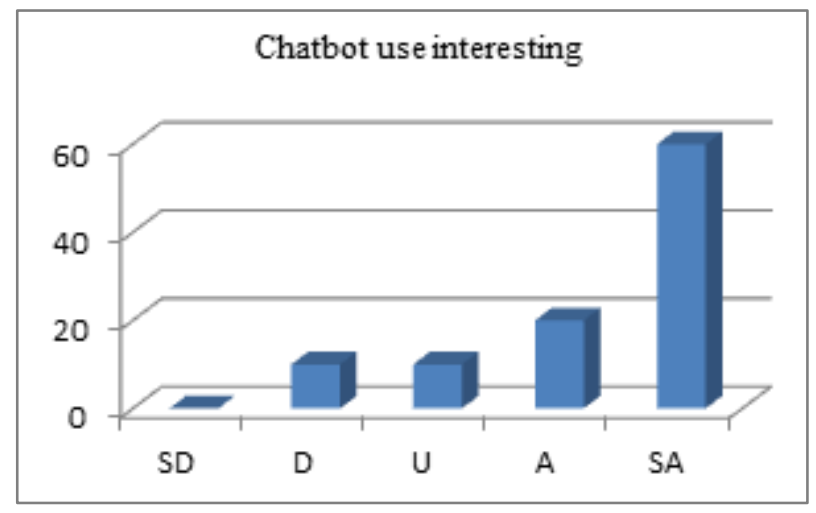

Item 2. Chatbot use is interesting

A majority of the teachers agreed that chatbot use is interesting. 


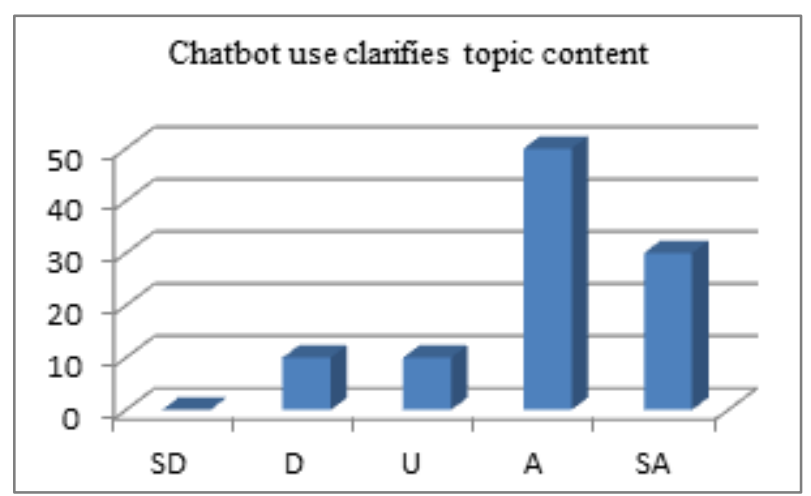

Item 3. Chatbot use clarifies topic content

A majority of the teachers agreed that chatbot use clarifies topic content.

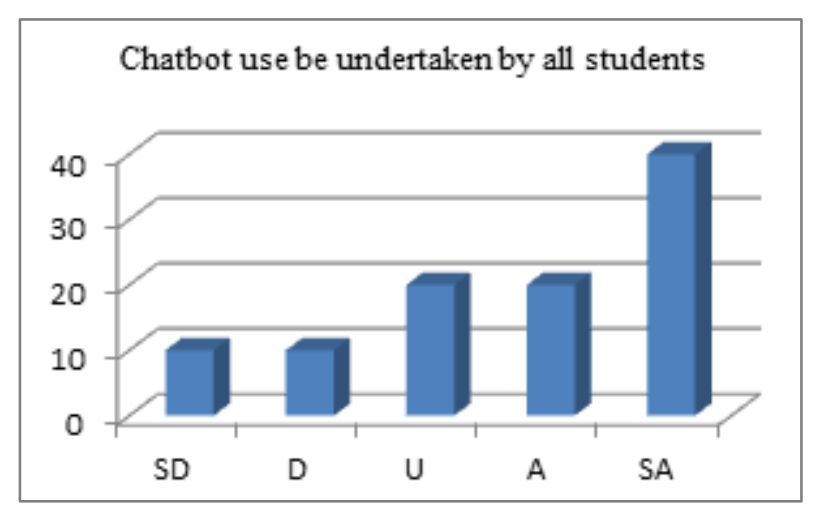

Item 4. Chatbot use be undertaken by all students

A majority of the teachers agreed that chatbot use be undertaken by all students.

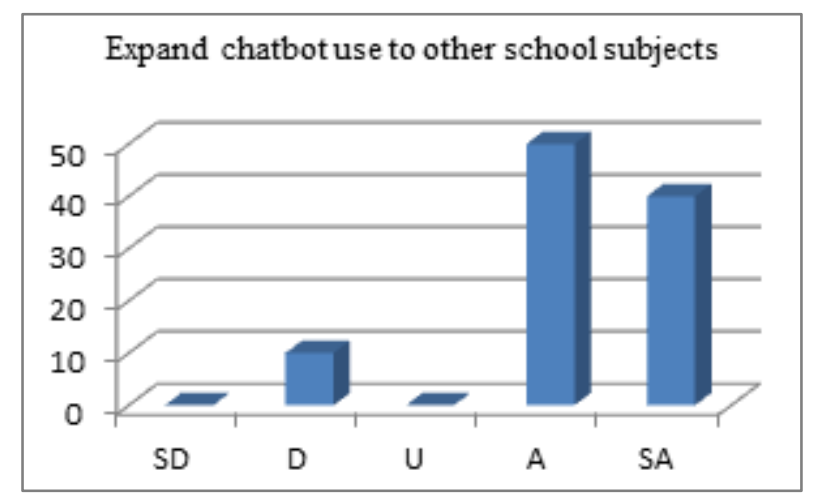

Item 5. Expand Chatbot use to other school subjects

The majority of teachers agreed that chatbot use be expanded to other school subjects.

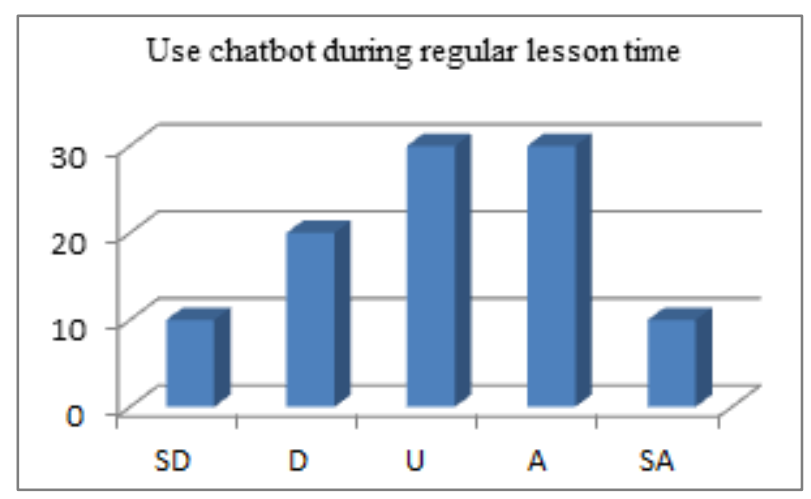

Item 6. Use chatbot during regular lesson time

Teachers have reservations about using a chatbot during regular lesson time.

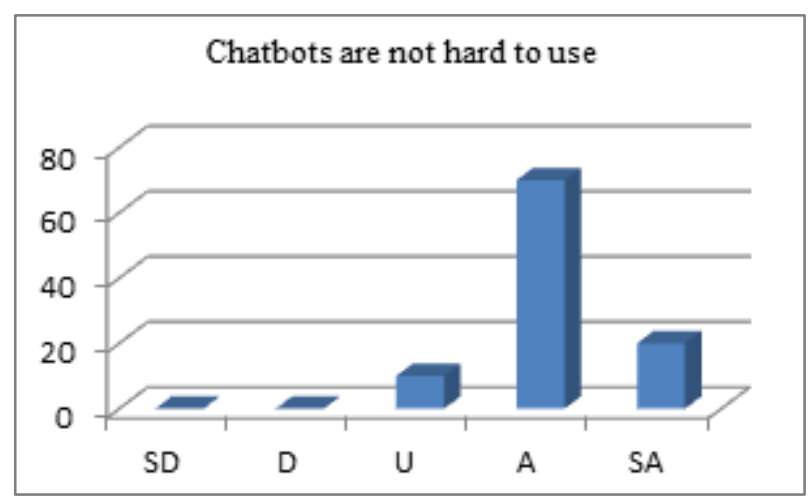

Item 7. Chatbots are not hard to use

A majority of teachers agreed that chatbots are not hard to use.

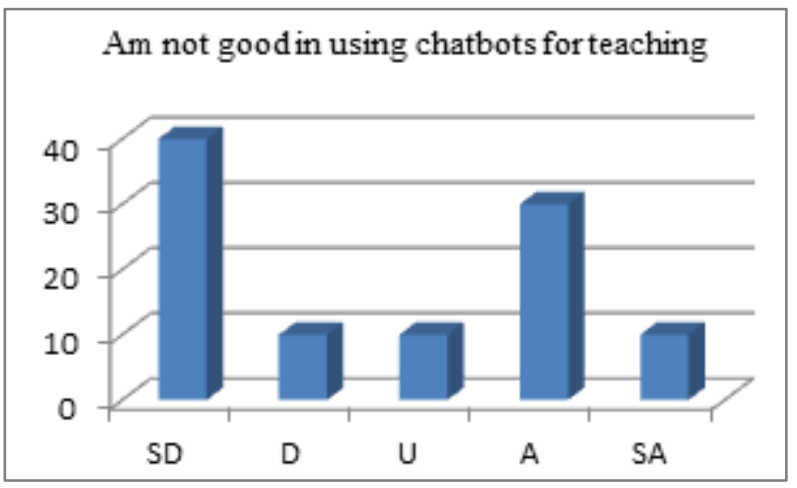

Item 8. Am not good in using chatbots for teaching

The majority of teachers disagreed that they were not good in using chatbots for teaching. 


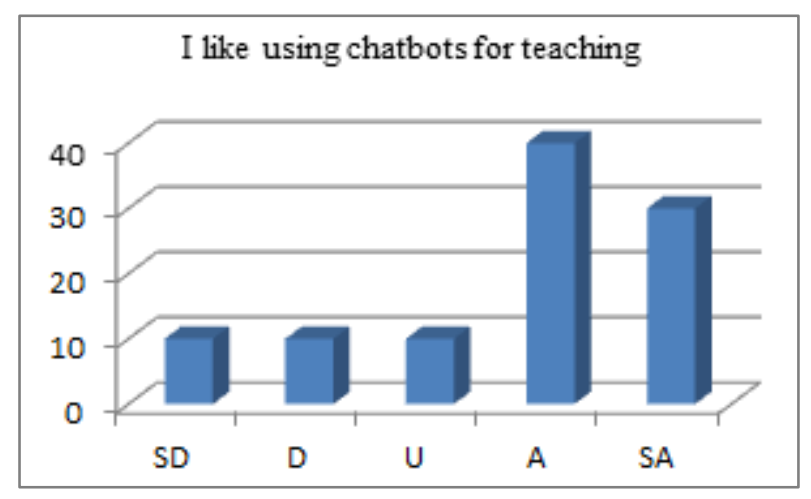

Item 9. I like using chatbots for teaching

The majority of teachers agreed that they liked using chatbots for teaching.

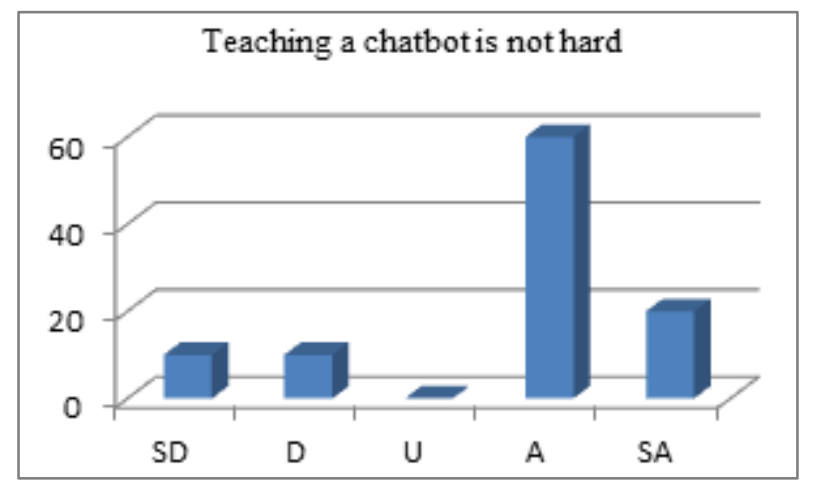

Item 10. Teaching a chatbot is not hard

A majority of the teachers agreed that teaching a chatbot is not hard.

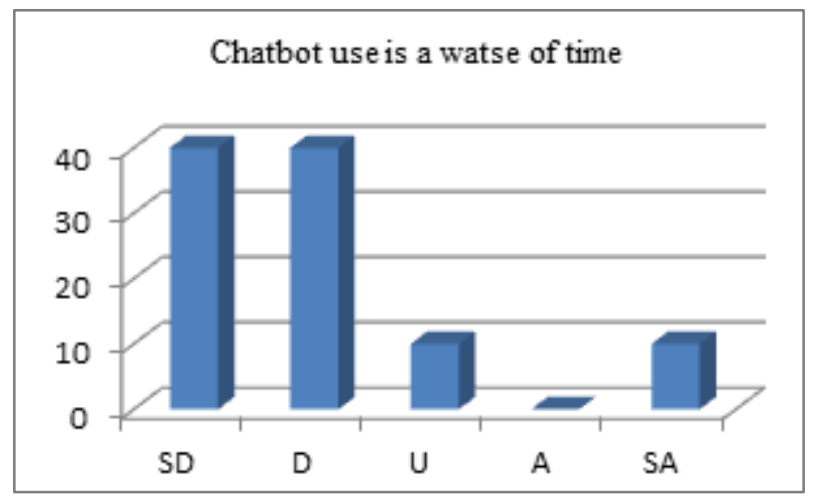

Item 11. Chatbot use is a waste of time

A majority of the teachers did not think that chatbot use is a waste of time.

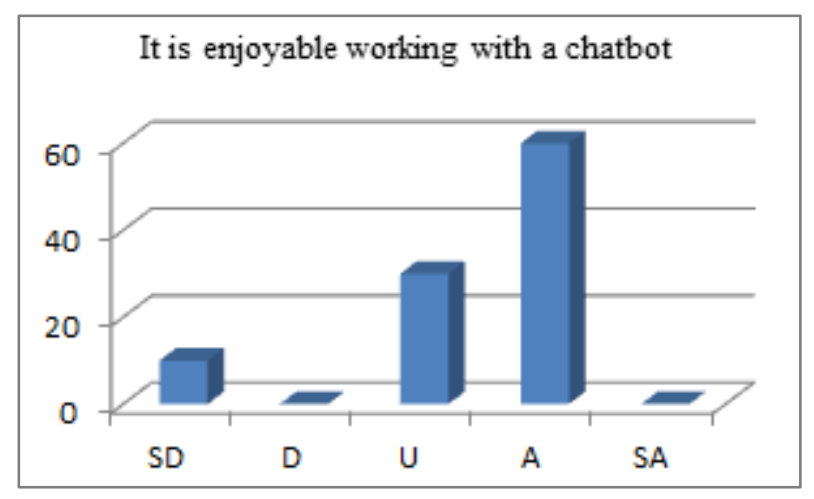

Item 12. It is enjoyable working with a chatbot

A majority of the teachers agreed that it was enjoyable working with the chatbot.

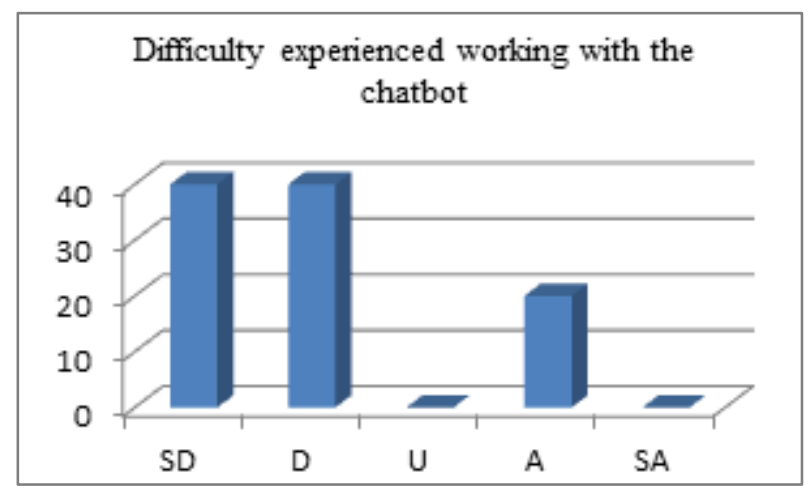

Item 13. Difficulty experienced working with the chatbot

A majority of the teachers experienced little difficulty working with the chatbot.

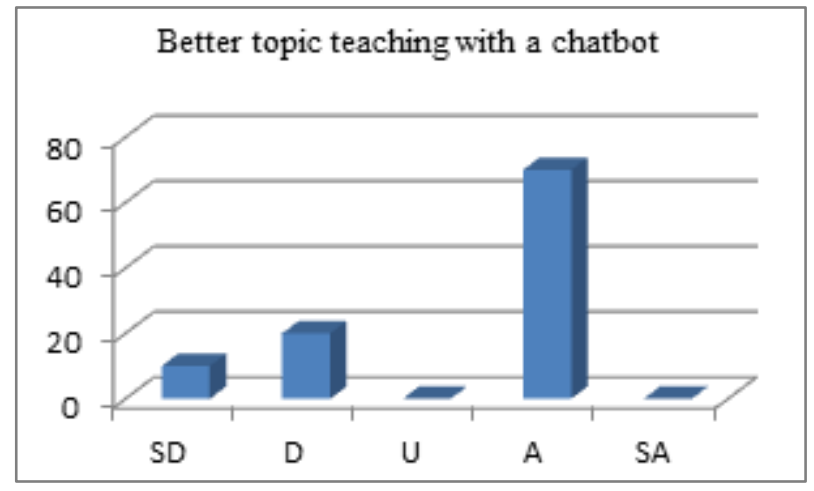

Item 14. Better topic teaching with a chatbot

A majority of the teachers agreed that there is better topic teaching with the chatbot. 


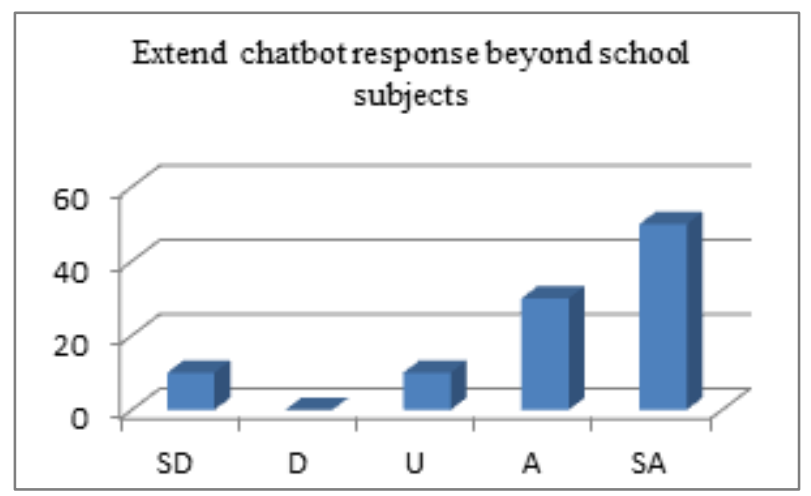

Item 15. Extend chatbot response beyond school subjects

A majority of teachers felt that chatbot responses should be extended beyond school subjects.

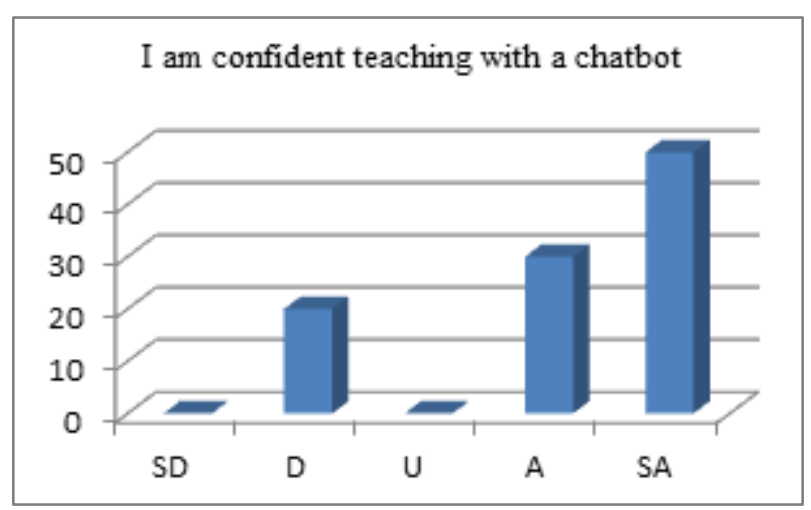

Item 16. I am confident teaching with a chatbot

The teachers were confident teaching with the chatbot.

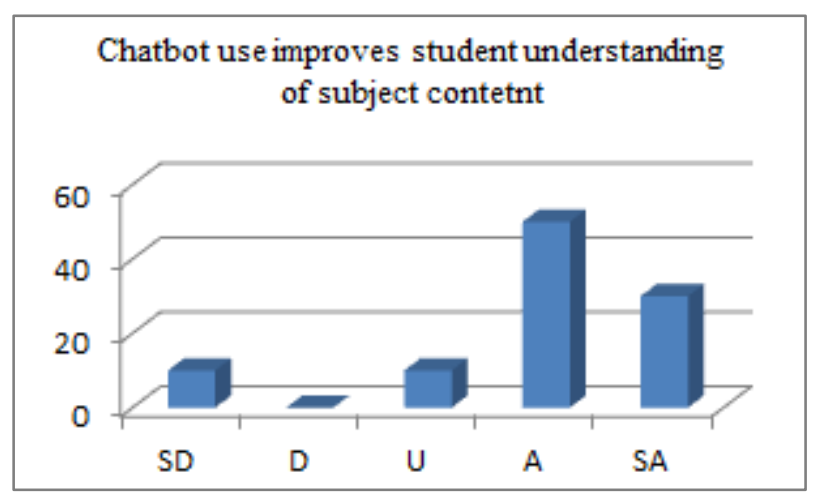

Item 17. Chatbot use improves student understanding of subject content

A majority of the teachers felt that chatbot use improves student understanding.

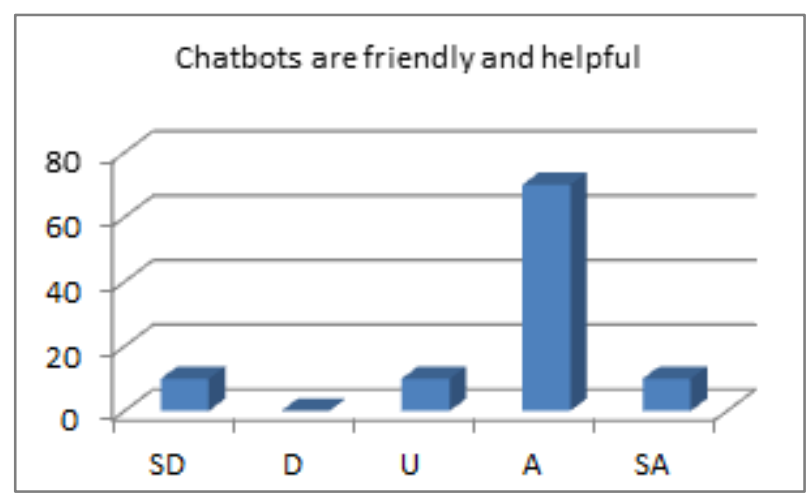

Item 18. Chatbots are friendly and helpful

A majority of teachers found the chatbot friendly and helpful. 
The individual and overall attitude scores for attitude questionnaire items for the teachers who responded to the questionnaires in the two participant schools are presented in Table 2 below.

Table 2. Teacher Attitude towards Chatbot Use in Instruction Score Summary

\begin{tabular}{|c|c|c|c|c|c|c|}
\hline & & $\mathrm{N}$ & Min & $\operatorname{Max}$ & Mean & Std. Deviation \\
\hline & Expand Chatbot Use To All Subject Topics & 10 & 4.00 & 5.00 & 4.4000 & .51640 \\
\hline & Chatbot Use Interesting & 10 & 2.00 & 5.00 & 4.3000 & 1.05935 \\
\hline & Chatbot Use Clarifies Topic Content & 10 & 2.00 & 5.00 & 4.0000 & .94281 \\
\hline & Chatbot Use Be Undertaken By All Students & 10 & 1.00 & 5.00 & 3.7000 & 1.41814 \\
\hline & Expand Chatbot Use To Other School Subjects & 10 & 2.00 & 5.00 & 4.2000 & .91894 \\
\hline & Use Chatbot During Regular Lesson Time & 10 & 1.00 & 5.00 & 3.1000 & 1.19722 \\
\hline & Chatbots Not Hard To Use & 10 & 3.00 & 5.00 & 4.1000 & .56765 \\
\hline & Am Not Good In Using Chatbots For Teaching & 10 & 1.00 & 5.00 & 2.6000 & 1.57762 \\
\hline & Like Using Chatbots For Teaching & 10 & 1.00 & 5.00 & 3.7000 & 1.33749 \\
\hline & Chatbot Teaching Not Hard & 10 & 1.00 & 5.00 & 3.7000 & 1.25167 \\
\hline & Chatbot Use Waste Of Time & 10 & 1.00 & 5.00 & 2.0000 & 1.24722 \\
\hline & Enjoyable Working With Chatbot & 10 & 1.00 & 4.00 & 3.4000 & .96609 \\
\hline & Difficulty Experienced Working With Chatbot & 10 & 1.00 & 4.00 & 2.0000 & 1.15470 \\
\hline & Better Topic Teaching With Chatbot & 10 & 1.00 & 4.00 & 3.3000 & 1.15950 \\
\hline & Extend Chatbot Response Beyond School Subjects & 10 & 1.00 & 5.00 & 4.1000 & 1.28668 \\
\hline & Confident Teaching With Chatbot & 10 & 2.00 & 5.00 & 4.1000 & 1.19722 \\
\hline Chatbot & Use Improves Student Understanding Of Subject Content & 10 & 1.00 & 5.00 & 3.9000 & 1.19722 \\
\hline & Chatbots Friendly And Helpful & 10 & 1.00 & 5.00 & 3.7000 & 1.05935 \\
\hline & Valid N (list wise) & 10 & & & & \\
\hline & Average attitude rating score & & & & 3.572 & \\
\hline
\end{tabular}

Source: Researcher's Field Data

The average attitude rating score obtained of 3.572 indicates that teachers have a positive attitude towards the use of chatbots in instruction. The interpretation and implication of this is that teachers are generally positively disposed to using chatbots in their teaching, and hence would welcome the technology and put it to use in their teaching.

The last item in the teacher attitude questionnaire was an open-ended item seeking to elicit suggestions from the teachers on how chatbot technology could be improved to better suit their needs. Their suggestions in descending order of frequency of mention are summarized in the chart 1. The top three improvement suggestions by teachers are that chatbot should come with question and answers already programmed to avoid time wastage, chatbot should come with question and answers already programmed to avoid student wrong answers, and chatbot to incorporate search capability comparable to web searches.
Teacher Chatbot Technology Improvement Suggestions

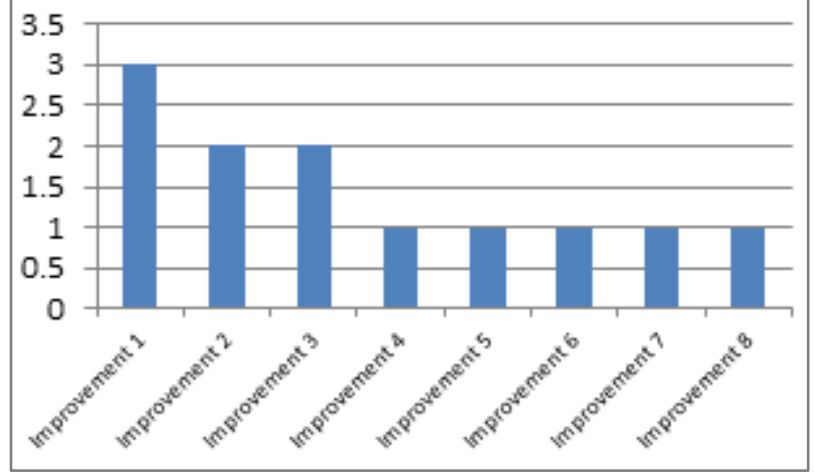

Chart 1. Teacher chatbot technology improvement suggestions 
Key:

\begin{tabular}{|c|l|}
\hline Improvement & \multicolumn{1}{|c|}{ Improvement Suggestion } \\
\hline 1 & $\begin{array}{l}\text { Chatbot should come with questions and answers } \\
\text { already programmed to avoid time wastage }\end{array}$ \\
\hline 2 & $\begin{array}{l}\text { Chatbot should come with question and answers } \\
\text { already programmed to avoid student wrong } \\
\text { answers }\end{array}$ \\
\hline 3 & $\begin{array}{l}\text { Chatbot to incorporate search capability } \\
\text { comparable to web searches }\end{array}$ \\
\hline 4 & Greater teacher training on chatbot use \\
\hline 5 & Extend to other students \\
\hline 6 & Extend to other schools \\
\hline 7 & More computers \\
\hline 8 & $\begin{array}{l}\text { Extend chatbot use to other school teaching } \\
\text { subjects }\end{array}$ \\
\hline
\end{tabular}

The response to the item that asked teachers whether or not they were willing to chat again with the chatbot was that the majority $(90 \%)$ were willing to chat again with the chatbot.

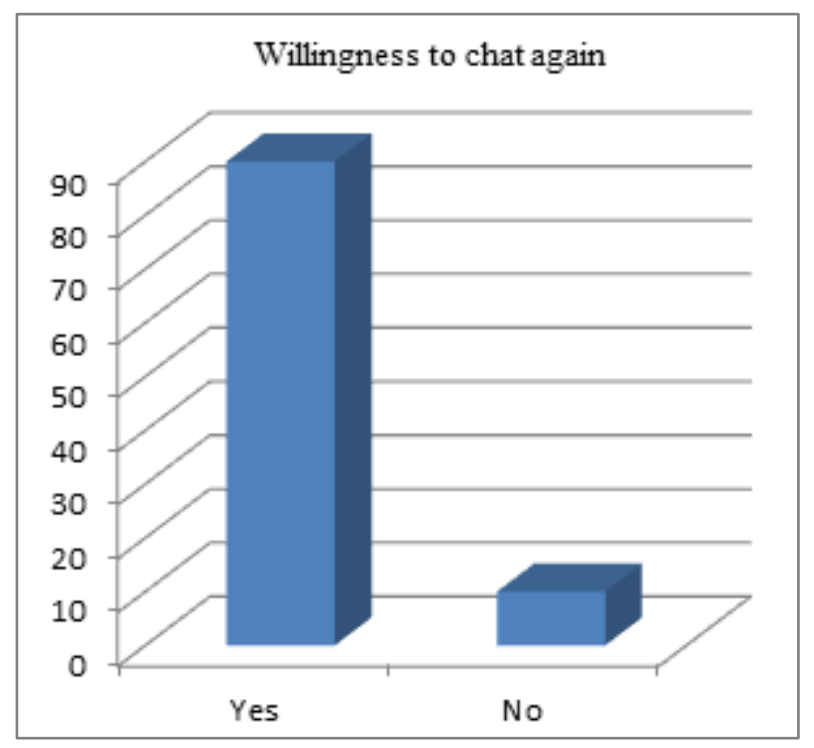

Item 19. Willingness to chat again with the chatbot

\section{Conclusions and Recommendation}

Teachers regard technology as being of benefit to them and to students [13, $43-45]$ and this regard extends to chatbot use in teaching and learning. Teacher high regard for chatbot technology use in teaching should therefore be capitalized upon to enable them start transforming teaching-learning environments from being the staple one of conventional approach to that based on social-constructivist ideas and thereby attain better teaching and learning outcomes. This requires that teachers be trained on proper educational technology integration strategies, for as has been noted in literature, 'investment in new ways of learning and teaching is not the same as investment in technology and infrastructure' [46, p23], with technology still predominantly being just availed to schools and little concerted effort being expended on teacher pedagogical views and actual school ICT integration issues [47].

Teachers are ambivalent when it comes to the question of when a chatbot should be used for teaching. The underlying motivation as pointed out by the teachers is that of time wastage in the face of need for syllabus coverage, packed school timetable, and preparation for nationally administered final exams. Ways therefore ought to be found to avail time in schools for adequate technology use in teaching through for example avoiding curriculum overload [48-49]. Teachers also expressed a requirement for a chatbot to be able to respond to topics outside school teaching-learning subject matter. Chatbots meant for use in teaching-learning, through proper knowledge base design, can therefore be enabled to serve as a means for teachers and students to access information beyond immediate school learning content and affairs.

Concerning the top three improvement suggestions by teachers (chatbot should come with question and answers already programmed to avoid time wastage, chatbot should come with question and answers already programmed to avoid student wrong answers, and chatbot to incorporate search capability comparable to web searches), a balance ought to be struck between providing no content, some content, and full content pertaining to teaching-learning topics in educational chatbots. Some content is ideal, to cater for time constraints and wrong student answers. Full content is not ideal, as this would take away the element of social knowledge construction by students and teachers when using a chatbot for teaching-learning activities within a social-constructivist based teaching-learning environment. Search features to enable the chatbot to undertake internet searches is important, as this would improve the learning curve of a given chatbot rapidly and thereby extend the comprehensiveness of its responses to teacher and student questions.

\section{REFERENCES}

[1] Kerly, A., Hall, P., \& Bull, S. (2007). Bringing chatbots into education: Towards natural language negotiation of open learner models. Knowledge-Based Systems, 20(2), 177185 .

[2] Dryden, G. (2008). Make Aiml: An AIML creation tool. Retrieved $\quad 10^{\text {th }} \quad$ October 2009 from: http://makeaiml.aihub.org/tutorials/aiml_template.php.

[3] Wang, Y. (2008). Designing Chatbot Interfaces for Language Learning: Ethnographic Research into Affect and User's Experiences. The University of British Columbia, Vancouver.

[4] Abu Shawar, B and Atwell, B. (2007). Chatbots: Are They Really Useful? LDV-Forum 2007 - 22 Band (1), 29-49

[5] Abu Shawar, B. (2005). A Corpus Based Approach to 
Generalising a Chatbot System. Doctoral Thesis, University of Leeds, School of Computing. Retrieved $8^{\text {th }}$ November 2011 from:

http://www.comp.leeds.ac.uk/research/pubs/theses/abusha war.pdf

[6] McNeal \& Newyear (2013). Introducing Chatbots in Libraries. Retrieved $20^{\text {th }}$ February 2015 from: https://journals.ala.org/index.php/ltr/article/view/4504/528

[7] Kowalski, S., Hoffman, R., Jain, R. \& Mumtaz, M. (2011). Using Conversational Agents to Help Teach Information Security Risk Analysis. SOTICS 2011: The First International Conference on Sociol Eco-Informatics. Retrieved 22nd June 2012 from: www.thinkmind.org/download.php?articleid =sotics_2011_4_30

[8] Chopra, S., Gianforte, R., \& Sholar, J. (2016.). Meet Percy: CS 221 Teaching Assistant Chatbot. ACM Transactions on Graphics, Vol. 1, No. 1, Article 1, Publication date: December 2016.

[9] Jia \& Chen (2009). Motivate the Learners to Practice English through Playing with Chatbot CSIEC. In Proceedings of the 3rd international conference on Technologies for E-Learning and Digital Entertainment pp.180 191.

[10] Kerfoot, B, P., Baker, H., Jackson, T. L., Hulbert, W. C., Federman, D. D., Oates, R. D., \& DeWolf W. C. (2006). A Multi-institutional Randomized Control Trial of Web-based Teaching to Medical students. Academic Medicine 81(3). 224-230.

[11] Knill, O., Carlson, J., Chi, A. and Lezama, M. (2004). An Artificial Intelligence Experiment in College Math Education. Havard Mathematics Department.

[12] Murithi, N., \& Indoshi, F. C. (2011). Attitude of Teachers and Students towards Use of Computers in Teaching of Computer Studies Curriculum in Secondary Schools. International Journal of Current Research Vol. 3, Issue, 11, pp.191-195, November, 2011. Retrieved $24^{\text {th }}$ July 2012 from: http://www.journalcra.com

[13] Mwei P. K., Too, J. K., \& Wando, D. (2011). The Effect of Computer-Assisted Instruction on Student's Attitudes and Achievement in Matrices and Transformations in Secondary Schools in Uasin Gishu District, Kenya. International Journal of Curriculum and Instruction Vol. 1(1), pp. 53 - 62, April 2011. Retrieved $11^{\text {th }}$ June 2011 from: http://www.muk.ac.ke/ijci

[14] Osodo, J., Indoshi, F. C., \& Ongati, O. (2010). Attitudes of Students and Teachers towards Use of Computer Technology in Geography Education. Educational Research Vol. 1(5) pp. 145-149. Retrieved 24th July 2012 from: http://www.interesjournals.org/ER

[15] Nchunge, D. M., Sakwa, M., \& Mwangi, W. (2012). User's Perception on ICT adoption for Education Support in Schools: A Survey of Secondary School Teacher's in Thika District Kenya. International Journal of Humanities and Social Science, 2(10), 17-29.

[16] Hennessy, S., Harrison, D., \& Wamakote, L. (2010). Teacher factors influencing classroom use of ICT in Sub-Saharan Africa. Itupale Online Journal of African
Studies, 2(1), 39-54.

[17] Sabzian, F., \& Gilakjani, A. P. (2013). Teachers' attitudes about computer technology training, professional development, integration, experience, anxiety, and literacy in English language teaching and learning. International Journal of Applied Science and Technology, 3(1). Retrieved from http://ijastnet.com/journals/ Vol_3_No_1_January_2013/9.pdf

[18] Albirini, A. (2006). Teachers' attitudes toward information and communication technologies: the case of Syrian EFL teachers. Computers \& Education, 47(4), 373-398. https://doi.org/10.1016/j.compedu.2004.10.013

[19] Sabzian, F., Gilakjani, A. P. (2013). Teachers' Attitudes about Computer Technology Training, Professional Development Integration, Experience, Anxiety, and Literacy in English Language Teaching and Learning. International Journal of Applied Science and Technology Vol. 3 No. 1; January 2013

[20] Seyoum, A. F. (2004). Key issues in the implementation and integration of ICT in education system of the developing countries. Downloaded On, 11(7), 2011

[21] Tinio, V. L. (2003). ICT in Education. e-ASEAN Task Force. Retrieved from http:/unpan1.un.org/intradoc/groups/public/documents/un pan/unpan037270.pdf

[22] Fu, J. S. (2013). ICT in Education: A Critical Literature Review and its Implications. International Journal of Education and Development Using Information and Communication Technology, 9(1), 112.

[23] Stratton C (2003). PyAIML (a.k.a. Program Y): A Python AIML Interpreter Downloaded on 12/11/2009 from: http://pyaiml.sourceforge.net/

[24] Abdul-Kader, S. A., \& Woods, J. Survey on Chatbot Design Techniques in Speech Conversation systems. (IJACSA) International Journal of Advanced Computer Science and Applications, Vol. 6, No. 7, 2015

[25] John-Steiner V, Mahn H (1996). Sociocultural approaches to learning and development: A Vygotskian framework. Educational Psychologist, 31 (3/4), 191-206.. Retrieved 2nd July 2012 from: http://webpages.charter.net/schmolze1 /vygotsky/johnsteiner.html

[26] Creswell, J. W. (2003). Research Design: Qualitative, Quantitative and Mixed Methods Approaches. SAGE Publications International Educational and Professional Publisher Thousand Oaks London New Delhi.

[27] Savenye, W. \& Robinson, R. (2001).Qualitative Research Issues and Methods: An Introduction For Educational Technologists.

[28] Zainal, Z. (2007). Case Study as a Research Method. Jurnal Kemanusiaan bil.9, Jun 2007. Retrieved $15^{\text {th }}$ December 2017 from:

http://psyking.net/htmlobj-3837/case_study_as_a_research _method.pdf

[29] Anwar Sheik, M., \& Bibi, S. (2005). Research Methods and Skills Module. Retrieved $15^{\text {th }}$ February 2013 from: http://www.scribd.com

[30] White, H., \& Sabarwal, S. (2014). Quasi-experimental 
design and methods. Methodological Briefs: Impact Evaluation, 8. Retrieved from https://beamexchange.org/uploads/filer_public/63/94/6394 67e9-9bc1-45f6-bc3b-7c3e296e418b/ quasi-experimental_design_methods.pdf

[31] Harris, A. D., McGregor, J. C., Perencevich, E. N., Furuno, J. P., Zhu, J., Peterson, D. E., \& Finkelstein, J. (2006). The Use and Interpretation of Quasi-Experimental Studies in Medical Informatics. Journal of the American Medical Informatics Association, 13(1), 16-23. https://doi.org/10.1197/jamia.M1749

[32] Rogers, E. M. (1983). Diffusion of innovations (3rd ed). New York: London: Free Press; Collier Macmillan.

[33] Perkins, R. A. (2011). Using Rogers' Theory of Perceived Attributes as a Framework for Understanding the Challenges of Adoption of Open Educational Resources. International Journal of Humanities and Social Science, 1(18), 59-66.

[34] Sansoni, J. E. (2011). Questionnaire design and systematic literature reviews. Retrieved from http://ro.uow.edu.au/cgi/viewcontent.cgi?article=1124\&co ntext=ahsri

[35] Siniscalco, M. T., \& Auriat, N. (2005). Questionnaire Design. Quantitative Research Methods in Educational Planning, 1-92.

[36] Murithi, N., Gitonga, D., \& Kimanthi, P. (2013). School ICT Policy, A Factor Influencing Implementation of Computer Studies Curriculum in Secondary Schools. Retrieved from http://www.academia.edu/download/ 32788969/School_ICT_Policy_a_Factor_Influencing_Im plementation of $\bar{C}$ Computer_Studies Curriculum in Seco ndary_Schools..pdf

[37] Jain, V. (2014). 3D Model of Attitude. International Journal of Advanced Research in Management and Social Sciences. Retrieved 15 ${ }^{\text {th }}$ December 2017 from: http://garph.co.uk/IJARMSS/Mar2014/1.pdf

[38] Johns, R. (2010). Likert Items and Scales. SQB Methods Fact Sheet 1 (March 2010). Retrieved $15^{\text {th }}$ December 2017 from:

https://www.sheffield.ac.uk/polopoly fs/1.597637!/file/lik ertfactsheet.pdf

[39] Blau, I., \& Peled, Y. (2012). Teachers' Openness to Change and Attitudes towards ICT: Comparison of Laptop per Teacher and Laptop per Student Programs. Interdisciplinary Journal of E-Learning and Learning Objects, 8(1), 73-82.

[40] Papanastasiou, E. C., \& Angeli, C. (2008). Evaluating the use of ICT in education: Psychometric properties of the survey of factors affecting teachers teaching with technology (SFA-T3). Journal of Educational Technology \& Society, 11(1). Retrieved from http://www.jstor.org/stable/ jeductechsoci.11.1.69

[41] Taiwo, S. (2009). Teachers' Perception of the Role of Media in Classroom Teaching in Secondary Schools. TOJET: The Turkish Online Journal of Educational Technology, 8(1). Retrieved from http://search.proquest.com/openview/

$\mathrm{d} 404 \mathrm{c} 19 \mathrm{~d} 8 \mathrm{c} 25 \mathrm{bd} 72 \mathrm{~d} 2 \mathrm{ef} 965$ eaffd48c3/1?pq-origsite $=$ gscho lar\&cbl $=1576361$

[42] Tanui, E. K., Kiboss, J. K., Walaba, A. A., \& Nassiuma, D. (2008). Teachers' Changing roles in computer assisted roles in Kenyan secondary schools. Educational Research and Reviews, 3(8), 280.

[43] Heller, B., Proctor, M., Mah, D., Jewell, L., \& Cheung, B. (2005). Freudbot: An investigation of chatbot technology in distance education. In EdMedia: World Conference on Educational Media and Technology (pp. 3913-3918). Association for the Advancement of Computing in Education (AACE). Retrieved from https://www.researchgate.net/profile/Lisa_Jewell3/publicat ion/242084006 Freudbot An Investigation of Chatbot T echnology_in_Distance_Education/links/0deec5 $\overline{5} 284 \mathrm{f} 631 \overline{1} 5$ 78b000000.p $\overline{\mathrm{df}}$

[44] Kerly, A., Hall, P., \& Bull, S. (2007). Bringing chatbots into Education: Towards natural language negotiation of open learner models. Knowledge-Based Systems, 20(2), 177185 .

[45] Singh, T. K. R., \& Chan, S. (2014). Teacher Readiness on ICT Integration in Teaching-Learning: A Malaysian Case Study. International Journal of Asian Social Science, 4(7), 874-885.

[46] Ang'ondi, E. K. (2013). Teachers Attitudes and perceptions on the use of ICT in teaching and learning as observed by ICT champions. In Proc. 10th IFIP World Conference on Computers in Education, Torun. Retrieved from http://wcce2013.umk.pl/publications/v1/V1.3_100-Angodi -fullR-FPR.pdf

[47] Ilomäki, L. (2008). The effects of ICT on school: teachers' and students' perspectives. University of Turku: distribution: Turku University Library, Turku.

[48] Menjo, E. (2013). An Assessment of Effectiveness of the Secondary School Science Pedagogy and Curriculum Relevance to Students' Needs in Baringo Central, Kenya. Journal of Emerging Trends in Educational Research and Policy Studies, 4(3), 433.

[49] Muskin, J. A. (2015). Student Learning Assessment and the Curriculum: issues and implications. Educational Theory, 58(1), 63-82. 